\title{
Acil Servise Başvuran Hastalardaki Sesamoid Kemiklerin ve Aksesuar Kemikçiklerin Ayak ve Ayak Bileğindeki Görülme Sıklığının Belirlenmesi
}

\author{
Determination of Frequency of Sesamoid Bones and Accessory Ossicles in Foot and Ankle in Patients Admitted to \\ Emergency Service
}

${ }^{1}$ Afyonkarahisar Sağllk Bilimleri Üniversitesi, Tip Fakültesi, Anatomi Anabilim Dall, Afyonkarahisar, Türkiye

${ }^{2}$ Afyonkarahisar Sağlık Bilimleri Üniversitesi, Tip Fakültesi, Anatomi Anabilim Dalı, Afyonkarahisar, Türkiye

${ }^{3}$ Afyonkarahisar Sağlık Bilimleri Üniversitesi, Tip Fakültesi, Acil Tip Anabilim Dalı, Afyonkarahisar, Türkiye

Correspondence: Abdülkadir BİLİR Afyonkarahisar Sağlık Bilimleri Üniversitesi, Tip Fakültesi, Anatomi Anabilim Dalı, Afyonkarahisar, Türkiye e-mail: fztabdulkadirbilir@gmail.com

\section{Abdülkadir Bilir, Emre Atay, Ayşe Ertekin}

\section{Özet}

Aksesuar kemikçikler ve sesamoid kemikler, ayakta çeşitli hastalıklara neden olan ve kırıkları taklit eden kemikleşmesini tamamlamıș kemik yapılardır. Radyografilerde tesadüfen keșfedilirler ve çoğu zaman gözden kaçırılarak yanlıș teșhislere yol açarlar. Bu nedenle, acil servise ayak ve ayak bileği şikâyeti ile başvuran hastaların radyografi görüntülerinde aksesuar kemikçik ve sesamoid kemiklerin görülme sıklığının belirlenmesi amaçlandı. Acil Servisi başvuran hastalara ait anteroposterior, oblik ve lateral ayak grafileri (506) retrospektif olarak değerlendirildi. Aksesuar kemikçiklerin ve sesamoid kemiklerin varlığı, prevalansı, bir arada bulunuşu ve dağılımı cinsiyete ve ekstremite tarafına göre detaylı olarak analiz edildi. 506 ayak grafisinde, \%18.4 oranında aksesuar kemikçik, \% 86.4 oranında sesamoid kemik tespit edildi. En yaygın aksesuar kemikçikler; os naviculare accessorium (\%11.5), os peroneum (\%3.6), os trigonum (\% 1.8), os supranaviculare (\%0.4), os vesalianum (\%0.2), os supratalare (\%0.2), os subfibulare (\% 0.6 ) ve os calcaneus secundarius (\%0.2)'tur. Radyografilerin \%86.4'ünde halluks sesamoid gözlemlendi. Halluks'un interfalangeal sesamoid kemiği, radyografilerin \%2'sinde görüldü. Metatarsofalangeal sesamoid kemik insidansı MTP II'de \% 2, MTP IV’te \% 0.4 ve MTP V'te \% 6.7 olarak bulundu. Çalışmanın sonuçları literatürde belirtilen aralıklarda olmasına rağmen, çalışma grubunun farklı populasyon ve yaş gruplarından oluşması ve sadece acil servise başvuran hastaların dahil edilmesi nedeni ile diğer literatür raporlardan önemli ölçüde farklı göstermektedir.

Anahtar Kelimeler: Aksesuar kemikçikler; Anatomi; Acil servis; Sesamoid kemikler

\section{Abstract}

Accessory ossicles and sesamoid bones are bone structures that have completed ossification that mimic fractures and cause various diseases in the foot. They are discovered by chance on radiographs and are often overlooked, and lead to misdiagnosis. For this reason, it was aimed to determine the frequency of the accessory ossicles and sesamoid bones in the radiographic images of the patients who were admitted to the emergency department with foot and ankle complaints. Anteroposterior, oblique and lateral foot radiographs of patients (506) admitted to the Emergency Service were evaluated retrospectively. The presence, prevalence, coexistence and distribution of accessory ossicles and sesamoid bones were analyzed in detail according to gender and extremity sides. In 506 foot radiographs, accessory ossicles were detected in $18.4 \%$ and sesamoid bones in $86.4 \%$. The most common accessory ossicles were accessory navicular (11.5\%), os peroneum (3.6\%), os trigonum (1.8\%), os supranaviculare ( $0.4 \%)$, os vesalianum $(0.2 \%)$, os supratalare $(0.2 \%)$, os subfibulare $(\% 0.6)$ ve os calcaneus secundarius $(\% 0.2)$. We observed hallux sesamoid in $86.4 \%$ of radiographs. Interphalangeal sesamoid bone of the hallux was seen in $2 \%$ of radiographs. Incidences of MTP I were found as $2 \%$ in the MTP II, 0.4\% MTP IV and 6.7\% MTP V. In conclusion, although the results of the study are within the ranges stated in the literature, they differ significantly from other literature reports because the study group consisted of different population and age groups and only patients who applied to the emergency department were included.

Keywords: Accessory ossicles; Anatomy; Emergency service; Sesamoid bones. 


\section{Giriş}

Ayak aksesuar kemikçikleri ve sesamoid kemikler, ayak ve ayak bileği yakınında bulunan kortikasyonunu tamamlamış kemik yapılardır. Gelişimsel kemik varyasyonları olarak da tanımlanabilirler. S1klıkla doğuştan olmakla birlikte bazen de travma kaynaklı olabilirler $(1,2)$.

Aksesuar kemikçikler, genellikle avülsiyon kırıkları ile karıştırılırlar ve radyografilerde tesadüfen keşfedilirler. Çoğu zamanda gözden kaçırılarak yanlış teşhislere yol açarlar. Ayrıca semptomlara yol açarak altta yatan patolojiye katkıda bulunabilir veya bunları şiddetlendirebilirler. Örneğin, ağrılı kırıkların bir sonucu olarak bu kemikler enfekte olabilir veya yerinden çıkabilirler. Hatta bağ dokusu hastalıklarına bile neden olabilirler (3-5).

Sesamoid kemikler ise, kendi ossifikasyon merkezlerinden gelişen 5-10 $\mathrm{mm}$ çaplı yuvarlak veya oval şekilli kemiklerdir. Kısmen veya tamamen bir tendonun içerisinde gömülü olarak bulunurlar. Sürtünmenin azaltılmasında ve çekme açısının değiştirilmesinde aktif rol oynayarak tendonların zarar görmesini engellerler. Anatomik olarak, birinci metatarsofalangeal eklemin normal bir parçası olarak kabul edilir ve nadiren diğer ayak eklemlerinde görülürler $(4,6)$.

Aksesuar kemikçikler ve sesamoid kemikler, ayakta çeşitli hastalıklara neden olur ve ayak kemiklerinin kırılmasını taklit eder. $\mathrm{Bu}$ yüzden gereksiz ortopedik konsültasyonları ve yanlış tanıları azaltmak için bu kemiklerin anatomik yerleşimleri ve klinik önemleri iyi bilinmelidir $(1,2,7,8)$. Bu çalışmada, herhangi bir ayak ve ayak bileği şikâyeti ile acil servise başvuran hastaların aksesuar kemikçiklerinin ve sesamoid kemiklerinin cinsiyete, görülme frekansına, bir arada bulunmalarına ve ekstremite tarafına göre radyografi görüntüleri üzerinde retrospektif bir şekilde incelenmesi amaçlandi.

\section{Materyal ve Metot}

$\mathrm{Bu}$ çalışma, aksesuar kemikçiklerin ve sesamoid kemiklerin insidansını belirlemek amaciyla 2018-2021 tarihleri arasinda AFSU Sağlık Uygulama ve Araştırma Merkezi Acil Servisine ayak ve ayak bileği şikâyeti ile başvuran 506 hastanın (287 erkek, 219 kadın, yaş aralı̆̆ $1-79$ yaş) radyografileri görüntülerini üzerinde gerçekleştirildi. 506 hastanın anteroposterior, oblik ve lateral ayak grafileri her iki ayakta aksesuar kemikçiklerin (Şekil 1 ve 2) ve sesamoid kemiklerin (Şekil 3) varlığı, prevalansı, bir arada bulunuşu ve dağılımı açısından retrospektif olarak incelendi. Kemik yapısında anormal durumu olanlar (tümör, kist, kanama vb.), travma veya dejeneratif bozukluk kaynaklı kemik yapısının bütünlüğünde bozulma olanlar, radyolojik görüntüleri net olmayanlar ve ampütasyona uğrayanların görüntüleri çalışmaya dahil edilmedi.

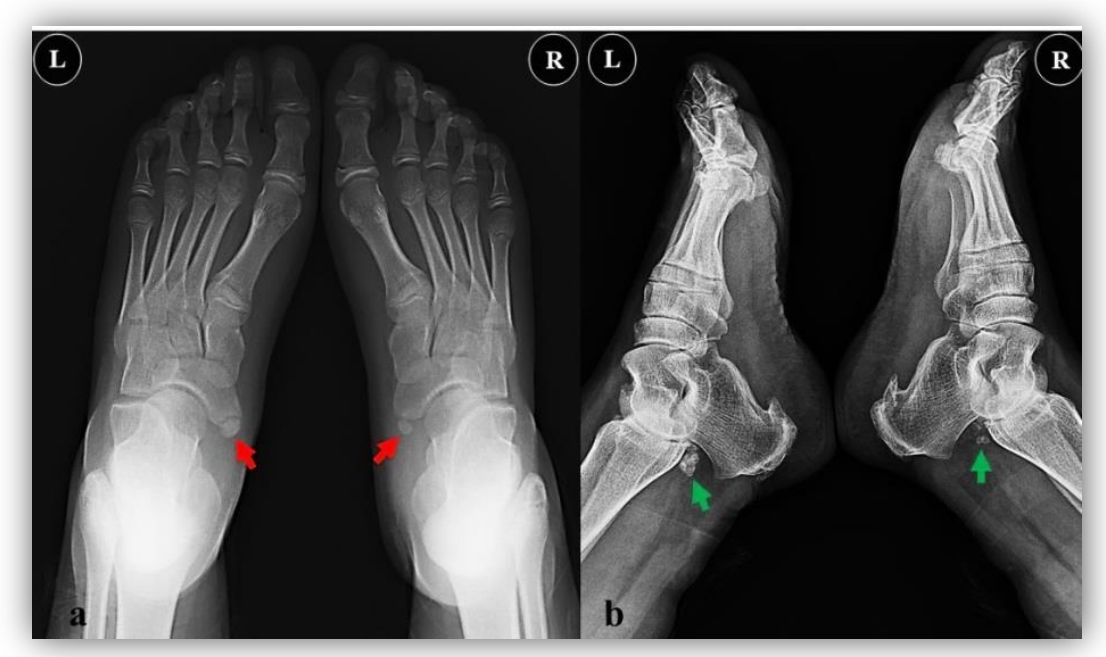

Şekil 1. (a) Os naviculare accessorium kırmızı okla gösterilmektedir. (b) Os trigonum yeşil okla gösterilmektedir. 


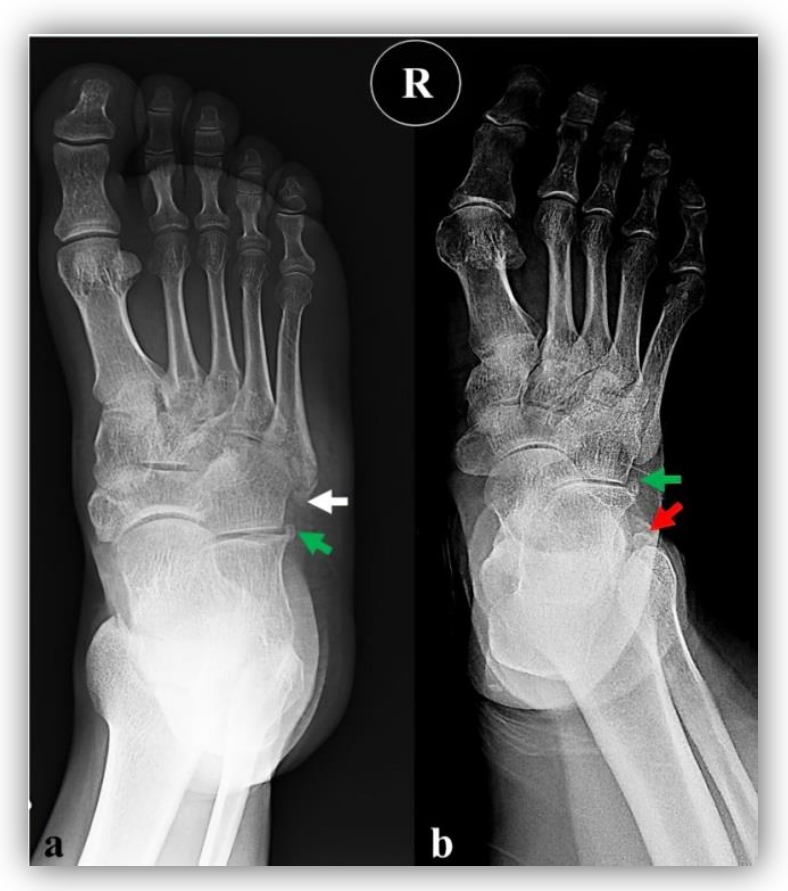

Şekil 2. (a) Os peroneum yeşil okla, os vesalianum beyaz okla gösterilmektedir. (b) Os peroneum yeşil okla, os subfibulare kırmızı okla gösterilmektedir.

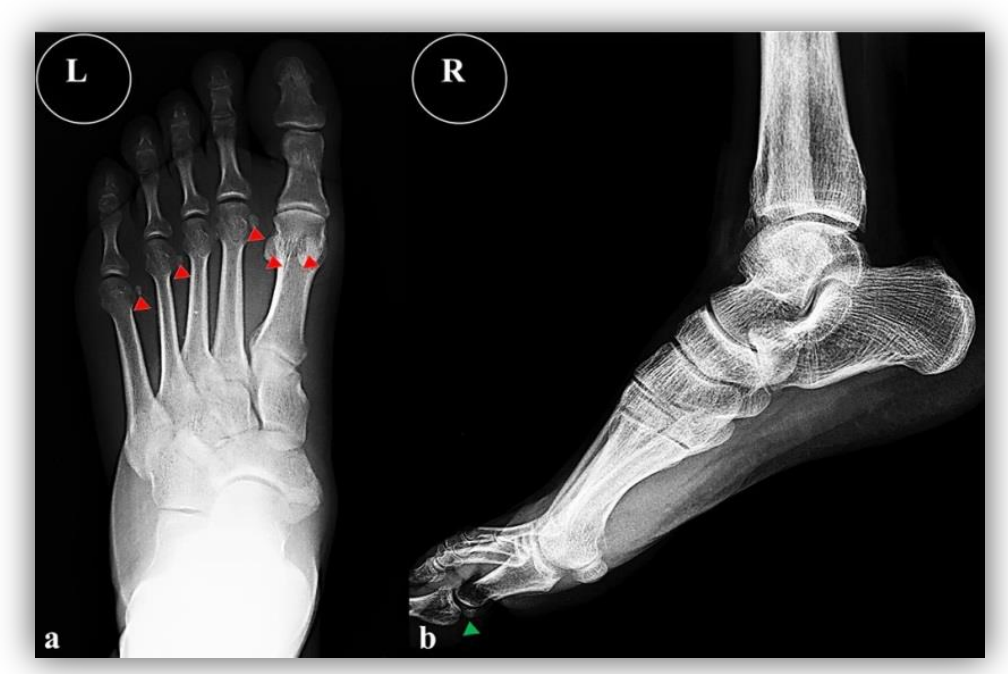

Şekil 3. (a) Metatarsofalangeal sesamoid kemikleri kırmızı ok başları ile gösterilmektedir. (b) Birinci proksimal interfalangeal eklem sesamoid kemiği yeşil ok başı ile gösterilmektedir.

Çalışma için AFSU Klinik Araştırmalar Etik Kurulu'ndan onay alındiktan sonra (Onay tarihi: 05.02.2021 ve Karar No: 2021-97), ayak ve ayak bileği radyografileri deneyimli üç araştırmacı (AB; Anatomist, $\mathrm{EA}$; Anatomist, AE; Acil Tip Uzmani) tarafindan interpacs programı kullanılarak bağımsız olarak değerlendirildi. Değerlendirme sonucunda ortaya çıkan anlaşmazlıklar, radyografilerin yeniden değerlendirildiği ve nihai bir kararın verildiğgi bir fikir birliği toplantısında tartışıldı. Tespit edilen sesamoid kemiklerin (metatarsofalangeal (MTP), interfalangeal (IP) ve distal interfalangeal (DIP) eklemlerde) ve aksesuar kemiklerin (Calcaneus secundarium, os trigonum, os peroneum, os vesalianum, os supranaviculare, os supratalare, os naviculare accessorium ve 
os subfibulare) ekstremite tarafina göre lokalizasyonları ve tipleri istatistiksel analizlerin yapılabilmesi için kaydedildi.

Verilerin istatistiksel analizi SPSS 20.0 paket programı (SPSS, Chicago, Illinois) ile yapıldı. Aksesuar kemikçiklerin ve sesamoid kemiklerin, cinsiyete, ekstremite tarafina ve dekatlar şeklinde ayrılan yaş gruplarına göre görülme sıklığı Ki-kare testi ile değerlendirildi. Kategorik veriler frekans ve yüzdeler olarak ifade edildi. Sonuçlar \%95 güven aralığında değerlendirilerek, $\mathrm{p}<0.05$ olan veriler istatistiksel olarak anlamlı kabul edildi.

\section{Bulgular}

Çalışmamızda 262'si sağ, 244'ü sol olmak üzere 506 olgunun ayak radyografi görüntüleri değerlendirildi ve 506 olgunun 93'ünde aksesuar kemikçikler tespit edildi. Çalışmamızda ayak bileği ve ayak bölgesinde en sik görülen aksesuar kemikçik aksesuar naviküler kemikçikti ve 116 olguda belirlendi. Ayrica 18 olguda os peroneum, 9 olguda os trigonum, 3 olguda os fibulare, 2 olguda os supranaviculare, birer olguda os vesalianum, os supratalare ve calcaneus secundarium tespit edildi. Aksesuar kemikçikler tüm kadın olguların \%8.1'inde ve tüm erkek olguların $\% 10.2$ 'sinde görüldü. Aksesuar kemikçiklerin cinsiyete, ekstremite tarafına ve yaş gruplarına göre dağılımı Tablo 1'de gösterilmiştir.

Sesamoid kemikler 506 olgunun \%86.4'ünde (437) mevcuttu. 437 olguda tespit edilen sesamoid kemiklerin dağılımı alt kısmında bulunduğu MTP'ye göre; MTP I (halluks sesamoidleri)'de 437 olgu, MTP V'te 34 olgu, MTP II'de 10 olgu ve MTP IV'te 2 olgu şeklindeydi. 56 olguda MTP I sesamoid kemiklerine eşlik eden sesamoid kemik belirlendi. 12 olguda bipartit medial halluks sesamoidleri gözlemlendi. Ayrıca birinci proksimal interfalangeal eklemlerinde sesamoid kemik 10 olguda görülürken, radyografilerin hiçbirinde ikinci, üçüncü, dördüncü ve beşinci ayak parmaklarının proksimal ve distal interfalangeal eklemlerinde sesamoid kemikler görülmedi. Ayak bölgesinin sesamoid kemikleri Tablo l'de detaylandırılmıştır.

Ekstremite tarafi, cinsiyet ve yaş gruplarına göre aksesuar kemikçiklerin ve sesamoid kemiklerin varlığ farkl1liklar istatistiksel olarak analiz edildi. Ekstremite tarafina (săg ve sol) göre aksesuar kemikçik ve sesamoid kemik görülme sıklığında anlamlı farklılık yoktu. Erkek ve kadın olgularda aksesuar kemikçiklerin ve sesamoid kemiklerin cinsiyetlere göre prevalansı genel olarak benzer iken, sadece birinci proksimal interfalangeal eklemde sesamoid kemikler kadınlarda erkeklere oranla istatistiksel olarak daha fazla görüldü $(p<0.05)$. Aksesuar kemikçik ve sesamoid kemiklerin yaş gruplarına göre dağ 11 ımı değerlendirildiğinde, 1-10 yaş grubunda MTP I sesamoid kemiklerinin yokluğunun $(\mathrm{p}<0.001), 11-20$ yaş grubunda aksesuar navicula kemikçiklerinin $(\mathrm{p}<0.05)$ ve $51-60$ yaş grubunda ise MTP V sesamoid kemiklerinin varlığının $(p<0.001)$ diğer yaş gruplarına göre istatistiksel olarak anlamlı derece daha fazla olduğu bulundu (Tablo 1).

\section{Tartışma}

Farklı aksesuar kemikçikler ve sesamoid kemikler, bipartisyonlar ve birliktelikler dahil olmak üzere ayak bileği ve ayakta birçok iskelet varyasyonu bulunabilir $(3,9)$. Çoğu aksesuar kemikçik ve sesamoid kemik herhangi bir şikâyete yol açmaz ve asemptomatik olarak kalır. Genellikle travma veya aşırı kullanım sonrası rutin radyolojik incelemelerde tespit edilerek dejeneratif değişikliklere veya ağrıya neden olurlar. Kurlabilir veya uyarabilirler ya da hareket aralı̆̆ını kısıtlayabilirler (10-13). Literatürde, ayak ve ayak bileğindeki aksesuar kemikçiklerin görülme oranı genel popülasyonda $\%$ 18-36.6 oranlarında değişkenlik gösterirken $(2,3,10)$, bizim çalışmamızda aksesuar kemikçiklerin görülme sıklığı \%18.4’tür.

Literatürde yapılan radyografi çalışmalarında os naviculare accessorium, os trigonum ve os perenoum prevelansı en yüksek olan aksesuar kemikçikler olarak bildirilmiştir. Fakat bu kemikçiklerin görülme sıklıkları farklı çalışmalarda değişkenlik göstermektedir $(1,3,6,13-15)$. 


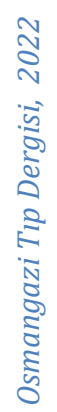

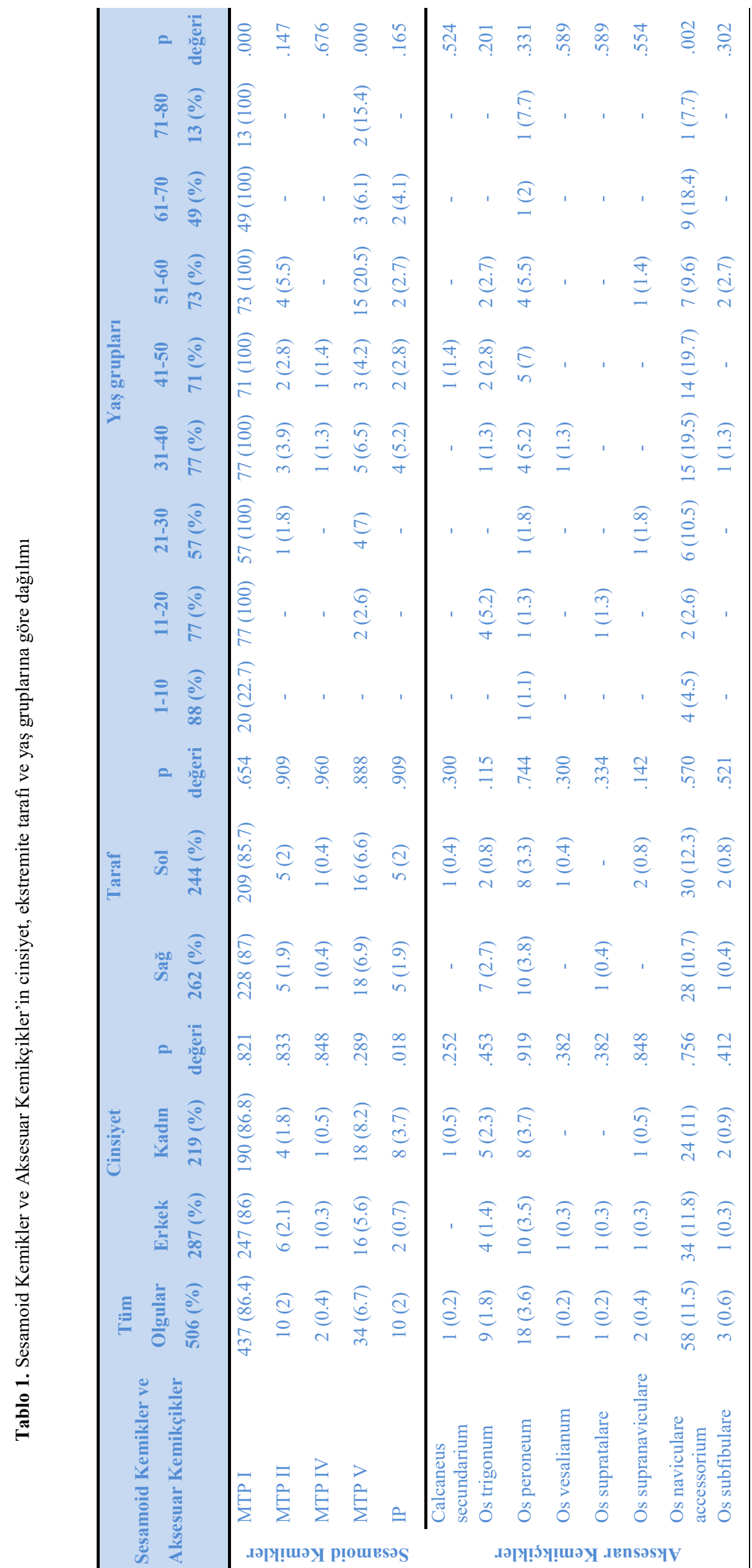


Os naviculare accessorium, musculus (m) tibialis posterior'un tendonu içinde ve/veya os naviculare'ye yapışmasına yakın bir yerde bulunur $(2,3,10,11,16)$. Görülme insidans1 \%4-21 arasında değişkenlik göstermektedir (2). Os peroneum, articulatio (art) calcaneocuboidea'nın bitişiğinde, m. peroneus longus tendonu içerisine gömülü yuvarlak veya oval şekilli bir sesamoid kemiktir. Semptomatik hale gelebilir, lateral ayak ağrısı ve ağrılı os peroneum sendromu olarak da bilinen hassasiyet olarak kendini gösterir $(17,18)$. Kolaylıkla bir avülsiyon kırığg olarak yanlış yorumlanabilir ve prevalansı \%3- 26 arasindadır $(3,11)$. Os trigonum, ayak bölgesinde talusun arka tarafinda bulunan üçgen veya oval şeklinde görülen en büyük aksesuar kemikçiklerden biridir. Kemik ve talus arasında bir senkondroz vardir $(4,6,16)$. \%1-25 arasında değişkenlik gösteren bir prevalansa sahiptir. Arka ayak bileği ağrısı ve şişlik olarak kendini gösteririr. Çoğu zaman tekrarlayan plantar fleksiyonla ilişkili posterior impingement sendromuna neden olabilir $(19,20)$.

Os naviculare accessorium, os peroneum ve os trigonum'un görülme sıklığı, Coskun ve ark.'1n (1) Türk populasyonundan 984 olgu ile yaptıkları çalışmalarında sırasıyla \%11.7, $\% 4.7$ ve $\% 2.3$ oranında iken, Longo ve ark.'1n (8) İtalyan porpulasyonundan 505 halluk vaguslu kadın olgu ile yaptıkları çalışmalarında sırasıyla \%6.7, \%7.9 ve \%6.7 oranında, Koo ve ark.'in (21) Kore populasyonundan 257 artrit hastaları ile yaptıkları çalışmalarında sırasıyla \%31.1, $\% 19.4$ ve $\% 5.8$ oranında tespit edilmiştir. Bizim çalışmamızda ise, bu aksesuar kemikçiklerin görülme oranları sırasıyla, $\% 11.5, \% 3.6$ ve $\% 1.8$ belirlenmiş olup, literatürle uyumlu olarak os naviculare accessorium en s1k görülen aksesuar kemikçiklerden biri olmuştur.

Os vesalianum, os supratalare, os supranaviculare, os calcaneus secundarius ve os subfibulare gibi aksesuar kemikçiklerinin prevelansı çok yüksek olmamasına rağmen, radyografi ve MR görüntülerinde tespit edilen diğer aksesuar kemikçikler arasında yer almaktadır. Bu kemikçikler ayak grafilerinde çoğunlukla başka bir aksesuar kemik varlığında belirlenirken, nadiren tek olarak bulunurlar $(3,9,10)$. Os vesalianum, $\mathrm{m}$. peroneus brevis tendonu içinde, os metatarsale V'in tabanına yakın konumlanmış küçük bir aksesuar kemikçiktir. Tahmini prevalansı \%0.1-1 olan çok nadir bir aksesuar kemiktir. Bireylerin yaklaşık \%0.1-1'inde görülebilir ve os metatarsale V'in epifizinden ayırt edilebilir. Nadiren semptomlara neden olur $(19,22)$. Os supratalare, tipik olarak caput ve collum tali arasında dorsal yüzde bulunur ve caput tali'nin üzerinde distal olarak görülebilir. Eski, birleşmemiş bir avülsiyon kırığı ile kolayca karıştırılabilir. Ancak lateral grafilerde görülebilir. Tahmini prevalansı $\% 2$ 'dir ve nadir rastlantısal bir iskelet varyasyonudur $(3,4,15)$. Os supranaviculare, corpus navicula'nı dorsal yüzünün proksimal'inde yer alır. Genellikle asemptomatiktir ancak travma bağlamında os navicula veya caput tali'nin avülsiyon kırığ 1 olarak yanlış teşhis edilebilir. Nadiren semptomatik hale gelebilir. Bu durumda ise cerrahi rezeksiyon gerektiren dorsal ayak ağrısına neden olabilir. Tahmini prevalans yaklaşık \%1 ile 3.5'tir (16). Os calcaneus secundarius, calcaneus, os cubeideum, os navicula ve caput tali'nin arasındaki aralıkta yer alır. Daha çok üçgen olmasına rağmen yuvarlak olabilir. Ayakta nadir görülen bir aksesuar kemikçiktir. Klinik önemi yoktur ve tesadüfen rutin radyografilerde bulunabilir. Tahmini prevalans1 \%0.6-7'dir(3). Os subfibulare, lateral malleollus'un ucunun altında, yuvarlak veya virgül şeklinde bulunan bir aksesuar kemiktir. Tahmini prevelansı $\% 2.1$ olarak belirtilmiştir $(9,13)$.

Literatür çalışmalarında görülme sıklığı daha az olan aksesuar kemikçikler; Coskun ve ark.'ın (1) çalışmalarında os supranaviculare (\%1.6), os vesalianum (\%0.4), os supratalare $(\% 0.2)$ ve os subfibulare $(\% 0.2)$, Longo ve ark.'ın (8) çalışmalarında os supranaviculare $(\% 1.2)$, os vesalianum (\%8.5), ve os supratalare (\%2.6), Koo ve ark.'in (21) çalışmalarında os vesalianum (\%4.2), os subfibulare $(\% 0.3)$ ve os calcaneus secundarius $(\% 0.3)$ olarak bildirilmiştir. Bizim çalışmamızda ise os supranaviculare $(\% 0.4)$, os vesalianum $(\% 0.2)$, os supratalare $(\% 0.2)$, os subfibulare $(\% 0.6)$ ve os calcaneus secundarius $(\% 0.2)$ siklığ 1 daha az olan 
aksesuar kemikçikler olarak bulunmuştur. Genel olarak çalışmamız sonucunda tespit edilen aksesuar kemikçiklerin görülme sıklıkları literatürde belirtilen sinırlar içerisinde yer almaktadır. Fakat literatür çalışmaları arasındaki farklılıkları; ırklar arasındaki farklılıklar, çalışma gruplarının çeşitliliği (belirli hastalık sahibi/sağlıklı bireyler) veya belirli bir cinsiyet grubu etrafinda kümeleşmesinden kaynaklanmaktadır.

Ayrıca bu çalışmada sesamoid kemiklerin görülme sıklığının da gösterilmesi amaçlanmıştır. Yetişkin insan iskeletindeki sesamoid kemiklerin sayısı bireyler arasında büyük farklılıklar gösterebilir. $\mathrm{Bu}$ kemikçiklerin insan iskeletindeki patogenezinin nedeni ve kesin sayıs bilinmemektedir $(6,23,24)$.

Halluks sesamoidleri, alt ekstremiteyi etkileyen darbe yüklerinin dağıtılmasında kritik bir rol oynar ve patolojik durumlarında spor ve aktivitelerden önemli ölçüde uzaklaşmaya neden olabilir (25). Halluks sesamoidlerinin doğuştan yokluğu nadir bir varyasyondur. İskeletin normal bir parçası olarak kabul edilir. Fakat 10 yaş altı çocukların radyografilerinde görülmesi çok zordur (1,6,8). Longo ve ark.'ın (8) çalışmalarında (\%80) ve bizim çalışmamız (\%86.4) haricinde tüm literatür çalışmalarında halluks sesamoidleri tüm olgularda görülmüştür. $\mathrm{Bu}$ durum Longo ve ark. ve bizim çalışma grubumuzda kemik gelişimini tamamlayamamış olguların (15 yaşın altı bireyler) bulunmasından kaynaklanmaktadır.

Ayak bölgesinde bulunan diğer sesamoid kemikler nadiren görülürler. Medial tarafta lateral tarafa göre çok daha yaygın olmakla birlikte her zaman MTP sesamoid kemikleri ikinci ve beşinci parmaklarda diğer parmaklara göre daha baskındır $(1,23)$. İkinci, üçüncü, dördüncü ve beşinci MTP sesamoid kemiklerinin görülme sıklığı Kiter ve ark.'nın (6) çalışmalarında sırasıyla $\% 2.8, \% 0.5, \% 1$ ve $\% 15.1$ oranında, Coşkun ve ark.'nın (1) çalıșmalarında sırasıyla $\% 0.4, \% 0.2, \% 0.1$ ve $\% 4.3$ oranında, Longo ve ark.'1n (8) çalışmalarında sırasıyla $\% 3, \% 1.2, \% 1.8$ ve \%19.2 oranında ve Koo ve ark.'1n (21) çalışmalarında sırasıyla $\% 6.1, \% 0.6, \% 2.3$ ve $\% 27.3$ oranında belirlendiği bildirilmiştir. Bizim çalışmamızda ise ikinci, dördüncü ve beşinci MTP sesamoid kemiklerinin görülme oranları surasiyla, $\% 0.4, \% 2, \% 2$ olarak tespit edildi. Ayrıca Kiter ve ark. çalışmasında, beşinci MTP sesamoid kemiği istatistiksel olarak erkeklerde daha fazla tespit edilmiş iken, Çoşkun ve ark. (1)çalışmasında erkekler ve kadınlar arasında önemli bir fark görülmemiştir. Bizim çalışmamızda ise Kiter ve ark. çalışmasının aksine beşinci MTP sesamoid kemik kadınlarda istatistiksel olarak daha fazla bulunmuştur.

Literatürde bazı çalışmalarda halüsal interfalangeal sesamoidin çok nadiren görüldüğünü ve klinik olarak da çoğunlukla zararsiz olan bu sesamoid kemiğin zaman zaman gösterdiği semptomlarının anatomik, biyomekanik ve klinik patolojinin gelișimi ile ilişkili olduğunu bildirilmiştir. Hallukal IP sesamoid, ilk MTP ve hallukal IP eklemlerinin biyomekanik fonksiyonları üzerinde zararlı bir etkiye sahiptir. IP sesamoidler eklemde plantar ağrılı kallozitelere neden olabilir veya çıkık bir eklemde hapsolabilir $(26,27)$. Dharap ve ark.(28) \%3.9 oranında, Bizzaro (29) \%5 oranında, Jahss (30) \%13 oranında, Coşkun ve ark. (1) ise $\% 2$ oranında bulmuşlardır. $\mathrm{Bu}$ oran bizim çalışmamızda da Coşkun ve ark. çalışması ile uyumlu olarak $\% 2$ oranında tespit edilmiştir.

\section{Sonuç}

Sonuç olarak, yapılan bu çalışma acil servise başvuran hastaların ayak aksesuar kemikçikleri ve sesamoid kemiklerin görülme sıklığını yaş gruplarına göre ayrıntılı bir şekilde inceleyen rapor olarak karşımıza çıkmaktadır. Çalışmanın sonuçları literatürde belirtilen aralıklarda olmasına rağmen, çalışma grubunun farklı populasyon ve yaş gruplarından oluşması ve sadece acil servise başvuran hastaların dahil edilmesi nedeni ile diğer literatür raporlardan önemli ölçüde farklı göstermektedir. Bu farklılıklara rağmen, acil servise ayak ve ayak bileği şikâyeti ile başvuran hastalardaki aksesuar kemikçik ve sesamoid kemik sıklıkları belirlenmiştir. İnanıyoruz ki bu çalışmamız sıklıkla gözden 
kaçan aksesuar kemikçik ve sesamoid kemik bozukluklarının tanı ve tedavisinde

\section{KAYNAKLAR}

1. Coskun N, Yuksel M, Cevener M, et al. Incidence of accessory ossicles and sesamoid bones in the feet: A radiographic study of the Turkish subjects. Surg Radiol Anat. 2009;31:19-24.

2. Vora BMK, Wong BSS. Common accessory ossicles of the foot: Imaging features, pitfalls and associated pathology. Singapore Med J. 2018;59:183-9.

3. Mellado JM, Ramos A, Salvadó E, et al. Accessory ossicles and sesamoid bones of the ankle and foot: Imaging findings, clinical significance and differential diagnosis. Eur Radiol. 2003;13:164-77.

4. Coughlin MJ, Mann RA, Saltzman CL, et al. Sesamoid and accessory bones of the foot. In: Surgery of the foot and ankle. 8th ed. Amsterdam: Elsewier; 2006. p. 438-94.

5. Lawson JP. International Skeletal Society Lecture in honor of Howard D. Dorfman. Clinically significant radiologic anatomic variants of the skeleton. Am J Roentgenol. 1994;163:249-55.

6. Kiter E, Akkaya S, Kiliç BA, Demirkan F. Distribution of the metatarsophalangeal sesamoids in Turkish subjects. J Am Podiatr Med Assoc. 2006;96:437-41.

7. Alfaraj DN, Vilke GM. Tripartite Fracture of the Ulnar Sesamoid Bone of the Thumb. J Emerg Med. 2017;53:758-9.

8. Longo UG, Marinozzi A, Petrillo S, et al. Prevalence of accessory ossicles and sesamoid bones in hallux valgus. $J$ Am Podiatr Med Assoc. 2013;103:208-12.

9. Sarrafian SK. Anatomy of the foot and ankle. In: Sarrafianan SK, editor. Osteology. Philadelphia: Lippincott; 2012. p. 89-112.

10. Miller TT. Painful accessory bones of the foot. Semin Musculoskelet Radiol. 2002;6:153-61.

11. Chan BY, Keegan Markhardt B, Williams KL, et al. OS conundrum: Identifying symptomatic sesamoids and accessory ossicles of the foot. $\mathrm{Am} \mathrm{J}$ Roentgenol. 2019;213:417-26.

12. Shands ARJ, Wentz IJ. Congenital anomalies, accessory ossicles, and osteochondritis in the feet of 850 children. Surg Clin North Am. 1953;33:1643-66.

13. Tsuruta T, Shiokawa Y, Kato A, Matsumoto T, Yamazoe Y, Oike T, Sugiyama T, Saito M. Radiological study of the accessory skeletal elements in the foot and ankle (author's transl). Nihon Seikeigeka Gakkai Zasshi. 1981;55:357-70.

14. Kruse RW, Chen J. Accessory Bones of the Foot: Clinical Significance. Mil Med. 1995:1;160.

15. Cilli F, Akçaoglu M. The incidence of accessory bones of the foot and their clinical significance. Acta Orthop Traumatol Turc. 2005;39.

16. Guo S, Yan YY, Lee SSY, et al. Accessory ossicles of the foot-an imaging conundrum. Emerg Radiol. 2019;26:465-78. klinisyenlere özellikle de acil hekimlerine yardımcı olabilecek anatomik veriler sağlar.
17. Gökkuş K, Sagtas E, Demirci E, et al. Degenerative arthritis of pseudoarticulation between the os peroneum and cuboid: A rare cause of lateral foot pain. Foot Ankle Surg. 2015; 21:e9e11.

18. Sobel M, Pavlov H, Geppert MJ, et al. Painful Os Peroneum Syndrome: A Spectrum of Conditions Responsible for Plantar Lateral Foot Pain. Foot Ankle Int. 1994:28;15.

19. Nwawka OK, Hayashi D, Diaz LE, et al. Sesamoids and accessory ossicles of the foot: Anatomical variability and related pathology. Insights into Imaging. 2013;4:581-93.

20. Lee JC, Calder JDF, Healy JC. Posterior impingement syndromes of the ankle. Seminars in Musculoskeletal Radiology. 2008; 12:154-69.

21. Koo BS, Song Y, Lee S, et al. Prevalence and distribution of sesamoid bones and accessory ossicles of the foot as determined by digital tomosynthesis. Clin Anat. 2017;30:1072-6.

22. Boya H, Özcan Ö, Tandoğan R, et al. Os vesalianum pedis. J Am Podiatr Med Assoc. 2005; 95.6: $583-85$

23. Goldberg I, Nathan H. Anatomy and pathology of the sesamoid bones - The hand compared to the foot. Int Orthop. 987;11:141-7.

24. Sarin VK, Erickson GM, Giori NJ, Bergman AG, Carter DR. Coincident development of sesamoid bones and clues to their evolution. Anat Rec. 1999: 15;257:174-80.

25. Dedmond BT, Cory JW, McBryde A. The hallucal sesamoid complex. J Am Acad Orthop Surg. 2006; $14: 745-53$.

26. Davies MB, Dalal S. Gross anatomy of the interphalangeal joint of the great toe: Implications for excision of plantar capsular accessory ossicles. Clin Anat. 2005;18:239-44.

27. Roukis TS, Hurless JS. The hallucal interphalangeal sesamoid. J Foot Ankle Surg. 1996;35:303-8

28. Dharap AS, Al-Hashimi H, Kassab S, et al. Incidence and ossification of sesamoid bones in the hands and feet: A radiographic study in an Arab population. Clin Anat. 2007;20: 416-23.

29. Bizarro FRCS. On sesamoid and supernumerary bones of the limbs. J Anat. 1921;55:256.

30. Jahss MH. The sesamoids of the hallux. Clin Orthop Relat Res. 1981;157:88-96. 